\title{
Literatura de massa na escola: uma proposta de letramento literário
}

\author{
Mass literature at school: a literary literacy \\ proposal
}

\author{
Ana LÚCIA ESPÍNDOLA * \\ FLÁVIO AMORIM DA ROCHA *
}

Resumo: Este artigo discute a questão da literatura de massa presente nas leituras realizadas por jovens do ensino médio do IFMS, problematizando a queixa comum de professores ao denunciarem que tais jovens não são leitores. Os dados foram obtidos por meio de questionários aplicados a 166 estudantes e nos permitem indicar que obras populares ocupam um importante papel nas leituras que marcaram a vida desses sujeitos e podem vir a promover o letramento literário.

Palavras-chave: multimodalidade, letramento literário, literatura de massa.

\begin{abstract}
This paper discusses the presence of mass literature among IFMS high school students' reading choices, bringing up the issue concerning the lack of reading pointed commonly by teachers at school. The data was collected through a questionnaire replied by 166 students, which allows us to demonstrate that these popular books play an important role in the students' reading repertoire and may promote literary literacy.
\end{abstract}

Keywords: multimodality, literary literacy, mass literature.

\footnotetext{
* Professora da Universidade Federal de Mato Grosso do Sul.

** Professor do Instituto Federal de Mato Grosso do Sul - Campus Campo Grande.
} 


\section{s alunos de ensino médio não leem?}

Segundo dados divulgados pelo INAF (Indicador Nacional de Alfabetismo Funcional $^{1}$ ), em sua edição 2011/2012, houve um aumento considerável no número de pessoas alfabetizadas funcionalmente no país que passou de 61\% em 2001 para 73\% em 2012. Ao mesmo tempo, o número de analfabetos absolutos sofreu um decréscimo também considerável indo de $12 \%$ para $6 \%$ no mesmo período. Há todos aqueles que lutam por uma sociedade plenamente alfabetizada, motivos para comemorar, evidentemente. Entretanto, ainda que os dados apresentados possam trazer otimismo e esperança, outra questão precisa ser considerada: o número de pessoas que dominam plenamente a leitura e a escrita permanece inalterado durante o mesmo período, sendo de apenas $26 \%$, ou seja, apenas um entre quatro brasileiros é capaz de ler e compreender plenamente um texto.

Em sua tese de doutoramento, William Roberto Cereja (2004) demonstra a necessidade de uma redefinição no ensino de literatura no nível médio, visto que uma parte considerável dos concluintes desta etapa escolar não possui hábitos de leitura. Segundo o autor, diversos instrumentos de avaliação atestam o despreparo dos estudantes quanto às capacidades leitoras, considerando os diversos gêneros textuais.

No que tange ao gênero literário, Cereja pontua que os resultados de suas investigações "fazem supor que o ensino de leitura e a abordagem do texto literário não têm sido objeto central das aulas de literatura" (CEREJA, 2004: 17). Essa pode ser uma realidade ainda latente na escola, configurando-se em um campo importante para discussões acerca da abordagem desses textos nas disciplinas de língua portuguesa e literatura.

Na era digital, das amplas oportunidades de acesso à informação, da cultura participativa, a ideia de que o jovem não lê ainda se sustentaria?

Quando se fala em falta de leitura entre os jovens, a que leitura estamos nos referindo? Podemos ler diferentes tipos de textos em suportes também variados. As práticas de leitura são sempre sociais e, por isso mesmo, podem ser bastante diferenciadas em múltiplos contextos. Quando nos referimos a ler um

1 O Instituto Paulo Montenegro e a ONG Ação Educativa construíram o índice e os dados são obtidos por meio de pesquisa por amostragem em todas as regiões do país com pessoas de 15 a 64 anos desde 2001. 
cânone literário, uma mensagem de SMS, um post de uma rede social, uma receita culinária, um poema, ou mesmo exercícios escolares, estaríamos falando do mesmo ato de leitura? Acreditamos que não. Conforme esclarece Soares:

Ler só é verbo intransitivo, sem complemento, enquanto seu referente forem as habilidades básicas de decodificar palavras e frases: diz-se de alguém que sabe ler, assim, sem complemento, ou que não sabe ler, quando se quer com isso dizer que esse alguém é alfabetizado ou é analfabeto. Para além desse nível básico, ler como prática social de interação com material escrito torna-se verbo transitivo, exige complemento: o alfabetizado, o letrado lê (ou não lê) o quê? lê mal (ou lê bem) o quê? o jornal? o best-seller? Sabrina? Machado de Assis? Drummond? a revista Capricho? Playboy? Bravo? Caros Amigos? Veja, Isto é, Época? a conta de luz, de água, de telefone? a bula do remédio? o verbete do dicionário, da enciclopédia? Ler, verbo transitivo, é um processo complexo e multifacetado: depende da natureza, do tipo, do gênero daquilo que se lê, e depende do objetivo que se tem ao ler (SOARES, 2005: 135).

A partir disso, temos como objetivo neste texto apresentar e discutir a leitura da obra fílmica Jogos Vorazes por estudantes participantes de um projeto desenvolvido em uma escola secundária de Campo Grande, MS, discutindo a adaptação de obras impressas para outras linguagens, bem como o possível lugar da cultura dita 'de massa' na escola. Procuraremos abordar as características presentes na obra que, além de levar muitos telespectadores às salas de projeção, foi responsável pela visita de muitos leitores a livrarias de todo o país, fato esse que não deve ser ignorado e que pode configurar-se em elemento propulsor do letramento literário.

Entende-se por letramento literário o conceito defendido por Cosson (2012), para quem:

Ser leitor de literatura na escola é mais do que fruir um livro de ficção ou se deliciar com as palavras exatas da poesia. É também posicionar-se diante da obra literária, identificando e questionando protocolos de leitura, afirmando ou retificando valores culturais, elaborando e expandindo sentidos. Esse aprendizado crítico da leitura literária, que não se faz sem o contato pessoal com o texto enquanto 
princípio de toda experiência estética, é o que temos denominado aqui de letramento literário (Cosson, 2012: 120).

Em uma pesquisa realizada em 2012 no campus Campo Grande do Instituto Federal de Educação, Ciência e Tecnologia de Mato Grosso do Sul, no âmbito do programa de iniciação científica Pibic Jr., foi possível identificar o perfil de leitor dos alunos dos cursos de nível médio integrado, por meio de um questionário aplicado a 166 estudantes. Os alunos envolvidos no projeto solicitaram a voluntários de cada turma dos cursos de informática, eletrotécnica e mecânica que respondessem a um questionário sobre seus hábitos de leitura. Não foi estipulado um número fechado de estudantes por sala, visto que era de interesse que houvesse uma representação significativa do corpo discente. As dez perguntas foram elaboradas no formato múltipla escolha e contemplaram questões tais como: idade, tempo semanal de leitura, o que é lido, e fatores que podem influenciar os hábitos de leitura dos respondentes.

Ao analisarmos os dados, percebemos que $94 \%$ se dizem leitores, mas $67 \%$ relatam que leem por prazer em um período de até 4 horas semanais. 91\% dos respondentes acreditam que a leitura por prazer pode impulsionar a formação de um número maior de leitores. Ou seja, a leitura por fruição, independentemente do que é cobrado pelo professor, ocuparia, assim, papel de destaque, do ponto de vista dos entrevistados, no incentivo à leitura.

Diante desses dados e considerando o contexto de ensino da literatura na instituição, pode-se chegar à conclusão de que, em um projeto que visa formar técnicos para o mercado de trabalho, as disciplinas da área das ciências humanas tendem a perder um pouco o foco na escola, o que leva a literatura a ocupar um papel secundário ao dividir espaço, em uma mesma carga horária, com o ensino de gramática e produção textual, visto que são essas as habilidades cobradas em provas de concurso.

É possível que, ao serem trabalhadas pelo professor, as obras literárias estejam sendo abordadas como exemplos de uma prática voltada ao ensino da periodização literária, marcada pela memorização de datas e características dos respectivos movimentos que formam a história da produção de literatura no país, além da utilização do texto como suporte para o ensino de aspectos gramaticais. É inegável que os aspectos de formação da cultura brasileira e a gramática 
da língua são importantes, mas seriam eles os responsáveis por desenvolver no aluno o gosto pela leitura literária?

Por outro lado, não podemos nos esquecer do que salienta Oliveira (2008): os professores possuem uma precária formação, salários aviltados, longas jornadas de trabalho que podem levá-los a "reeditar situações sociais burocráticas" sem uma ação efetiva que leve ao conhecimento:

Esses professores, leitores restritos aos best-sellers, e aos clássicos escolares, tendem a ensinar a literatura a partir de um modelo historicista em moldes antigos e a atribuir a responsabilidade pelo fracasso do ensino ao desinteresse dos alunos e à suposta omissão parental na educação dos seus filhos. Além disso, indicam também a concorrência da cultura de massa, representada pela onipresença dos veículos de comunicação, como a televisão e a internet, como fatores desestimulantes a um modo de leitura que os alunos, supostamente, deveriam ser capazes de realizar, tipo de leitura que os próprios professores não costumam praticar. Ou seja, de modo geral, os docentes tendem a não enxergar nos estudantes os alunos que eles mesmos foram. (177-8)

A pesquisa desenvolvida no ambiente escolar aponta que, do universo de estudantes que responderam ao questionário, apenas $10 \%$ leem a literatura dita 'clássica' ou 'canônica', que, por sua vez, aparece pouco nos exemplos de livros citados como os que marcaram a história de leitura desses alunos. 90\% deles relatam que livros como Harry Potter, Percy Jackson e A Cabana, por serem instigantes, foram responsáveis por uma leitura mais prazerosa e divertida.

Consequentemente, dizer que o aluno não lê é incoerente com o que é expresso por eles quando questionados a respeito dos seus hábitos de leitura. A imagem de vários estudantes carregando calhamaços, como As Crônicas de Gelo e Fogo e Game of Thrones, também parece desmistificar a crença que temos na não-leitura. Qual seria, então, o problema com a formação de leitores nas escolas?

Alguns discursos são comumente reproduzidos pelos professores de literatura. Entre eles, a crítica ferrenha à cultura de massa. Muitas vezes, não se tem conhecimento das obras crucificadas, mas seria um absurdo perder tempo lendo-as, já que muitas pessoas foram cativadas e falam sobre elas. Se a grande maioria gosta e consome esses produtos, boa coisa não deve ser... 
Percebe-se, assim, que a problemática não está na falta de leitura, mas nas opções feitas pelo aluno que diferem daquilo que as instituições e os docentes esperam. $O$ grande incômodo passa a ser o que nossos alunos leem e por quem eles têm trocado autores 'sacralizados' como Machado de Assis e Guimarães Rosa.

\section{Literatura de massa na escola? Será?}

Com o intuito de procurar trazer para a escola a bagagem de leitura dos estudantes, nasce o Projeto Entreleituras, formado por três alunos bolsistas Pibic Jr. do IFMS e o professor orientador. São realizadas reuniões semanais para discussão de textos teóricos sobre leitura, seguidas da organização de mostras de filmes adaptados de obras 'de massa' e, também, da literatura canônica.

Frente à multimodalidade da expressão artística na contemporaneidade, as práticas de ensino não deveriam desconsiderar o fato de que a literatura pode ser veiculada em suportes distintos, além do impresso. Há, para citar poucos exemplos, adaptações de obras literárias para o cinema, para a televisão e para os quadrinhos. Com a evolução das mídias, a escola não poderia sofrer do mal da estagnação. Ora, se a sociedade tem se tornado cada vez mais visual, a formação do leitor passa, também, por um processo de mudanças. Os novos suportes de leitura propiciam experiências diferentes daquelas que nascem do contato com o objeto livro.

Gunther Kress (2000) defende que a comunicação da informação é mais eficiente no modo visual que no verbal e que, portanto, devemos repensar a linguagem como fenômeno multimodal. $\mathrm{O}$ autor afirma, ainda, que a semiose humana é como o corpo, sendo os meios de percepção de mundo os nossos sentidos - visão, olfato, paladar, tato e audição. As experiências de leitura passam a contemplar, assim, mecanismos que desafiam a organização grafocêntrica de nossas sociedades.

Acredita-se, portanto, que, ao promover discussões a respeito das obras que os estudantes leem, independentemente de seu modo de representação, seja possível compreender os fatores que motivam suas escolhas, bem como fazer delas um ponto de partida para promover o letramento literário, formando, as- 
sim, leitores que possam fruir das experiências suscitadas pela leitura, em suas diversas formas de circulação.

Para Paulino (2001), esse cidadão literariamente letrado seria aquele que, por meio da literatura, aceitasse que há um pacto ficcional estabelecido entre a narrativa e o leitor, a quem cabe recuperar valores culturais, considerando o trabalho estético da linguagem. Afinal, uma obra não é apenas seu enredo, mas um processo de construção poética para o qual as palavras empregadas e o estilo do autor constituem parte importante. A leitura deve instigar e desconstruir, causando rompimentos com ideias pré-concebidas, ampliando o horizonte de expectativas e o conhecimento de mundo do leitor.

A fim de que se atinja tal objetivo, a leitura literária também exige esforço. Levar o aluno ao gosto pela descoberta estética além do enredo deve ser um processo contínuo e dialógico, que pode cumprir um papel importante na futura escolha de textos pelo próprio aluno. $O$ trabalho com a linguagem pode vir a tornar-se um diferencial na decisão e análise das obras a serem lidas.

Ao abordar o discurso literário, o professor entra no campo da subjetividade (AZEVEDO, 2004), que permite discutir aspectos humanos relevantes não abordados nos manuais didáticos, como o processo de autoconhecimento, de busca pela identidade e as dificuldades em lidar com as paixões e emoções do homem. Percebe-se, dessa maneira, que o texto literário, responsável, segundo Candido (2004), pela humanização e desenvolvimento do senso crítico e estético do ser humano, desempenha importante papel na formação cidadã do aluno em idade escolar.

Partir do pressuposto de que obrigar o jovem leitor a apreciar José de Alencar e Lima Barreto vai fazer com que ele descubra nas obras de autores como esses os elementos subjetivos para a compreensão de si e do outro parece um tanto arriscado. Primeiramente, porque as obras literárias selecionadas do cânone estão distantes, do ponto de vista dos leitores, da realidade que os cerca e os temas não parecem interessá-los tanto quanto aqueles trazidos pelas obras de aventura e fantasia que os cativam. Contudo, o professor é aquele que pode desconstruir essa concepção e mostrar que uma boa obra é sempre atual. Não importa há quanto tempo foi escrita, se os temas que concernem à alma humana são bem trabalhados, pode-se afirmar a atemporalidade da obra literária. Além do mais, é extremamente importante que haja uma mediação entre a leitura e os leitores. Se o professor é um bom leitor e conhece as obras com as quais 
deseja trabalhar, não há porque não relacioná-las com as produções de massa, oferecendo ao aluno a possibilidade de falar, também, daquilo que despertou seu interesse. Desde que o processo não pare por aí, é claro.

Cosson (2012) defende que não se pode ignorar o cânone literário, já que ele carrega consigo a identidade cultural de um país e a maturidade do leitor depende do diálogo estabelecido com essa herança. A união em um mesmo espaço das obras que constam na ementa da disciplina de literatura e as obras de 'massa' podem, consequentemente, promover compreensão acerca da pluralidade da língua e da cultura de um povo.

\section{Leitores vorazes}

Até o presente momento, o projeto Entreleituras já exibiu três adaptações cinematográficas: $V$ de Vingança, Crepúsculo e Jogos Vorazes. No recorte que foi feito para este trabalho, selecionamos alguns trechos de discursos provenientes da discussão com os alunos que compareceram a uma dessas mostras.

Escrito por Suzanne Collins e publicado em 2010, Jogos Vorazes (Hunger Games) ganha sua versão cinematográfica em 2012. A obra conta a história de Panem e seus 13 distritos. No início da narrativa, é explicado que o décimo terceiro distrito havia se revoltado contra a Capital e, assim, para que todos se lembrem do respeito que devem aos governantes, todo ano acontecem os chamados Jogos Vorazes. Cada um dos 12 distritos restantes deve enviar dois representantes, um homem e uma mulher, sorteados no dia da Colheita, a uma arena preparada para que uma luta seja travada até que sobreviva apenas uma pessoa. Esse sobrevivente, além de não participar de edições futuras dos jogos, garante melhorias para o seu distrito.

Os distritos são organizados hierarquicamente, sendo o primeiro o mais evoluído. As personagens centrais da narrativa, Katniss e Peeta, são do Distrito 12, onde há pobreza e exploração extrema. Todos os distritos trabalham para fornecer matéria prima à Capital. Cada um deles tem uma especialidade; a do Distrito 12 é a mineração.

Peeta e Katniss juntam-se aos outros participantes e os jogos começam sob o cuidadoso controle da Capital. Sendo a obra uma trilogia, o primeiro volume termina com a vitória dos tributos do Distrito 12 , após assumirem um romance 
sugerido pelos controladores do jogo. As regras são mudadas e é permitido que haja dois vencedores. O final da narrativa se dá quando ambos voltam, vitoriosos, para casa.

Jogos Vorazes, além de sucesso de bilheteria, foi um dos livros mais vendidos em 2012 e 2013, segundo a Revista Veja² ${ }^{2}$ Em seu ano de estreia, o romance vendeu mais de 200.000 cópias no Brasil e mais de 13 milhões de exemplares nos Estados Unidos. Não podemos desconsiderar que a obra tem sido responsável por despertar o interesse de um número grande de leitores. Mas o que faz com que isso aconteça?

Após a exibição do filme no primeiro semestre de 2014, o Entreleituras promoveu um debate sobre a recepção de Jogos Vorazes pelos estudantes. Selecionamos alguns trechos para tentarmos compreender o fenômeno de vendas, tanto em material impresso como em sua adaptação para o cinema.

Quando questionados a respeito do que leva as pessoas a assistirem ou lerem a obra, os estudantes disseram:

Acho que a linguagem chama atenção. Além de colocar um monte de gente que vai morrer, tem um romance. Aí vira uma febre (Estudante 1).

É modinha. Um lê e fala pro outro (Estudante 2)

Mas por que ser modinha tem que ser ruim? (Estudante 1)

Sempre existe aquela história... se é bom, pouca gente pode ter acesso. Por que isso? (Estudante 3)

É um filme e um livro feito pra ganhar dinheiro. (Estudante 2)

Percebe-se, com esses excertos, que os alunos reconhecem a obra como produção de massa e evidenciam o preconceito que existe quando se fala desse tipo de literatura. O que é considerado erudito é, muitas vezes, inacessível aos leitores. Dessa forma, quando um livro ou um filme atingem grande parcela da população, ele é imediatamente considerado inferior, se comparado à arte valorizada pela academia. Será mesmo que tudo o que chega para o grande público tem de ser ruim?

2 http://veja.abril.com.br/noticia/entretenimento/jogos-vorazes-lidera-lista-de-livros-maisvendidos-no-brasil (acesso em 04/10/2014). http://veja.abril.com.br/blog/meus-livros/best-seller/novo-filme-recoloca-trilogia-jogos-vorazesnos-mais-vendidos/ (acesso em 04/10/2014). 
Sobre a temática da obra, os alunos pontuaram:

O filme trata de um assunto que é do dia-a-dia de todo mundo. Os jogos chamam a atenção (Estudante 1).

O filme coloca de forma exagerada algumas coisas da nossa sociedade. Ele exagera alguns pontos sociais. A questão da mídia, o gosto das pessoas, o controle, o amor... isso reduz a questão política para o entretenimento. Para mim, a obra fala da alienação (Estudante 2).

Para mim, é a política do pão e circo. O pão são os programas do governo, os projetos e as bolsas. O circo é a Copa do Mundo. A seleção ganhou, o povo fica feliz (Estudante 3).

Existe a questão política, mas tem que extrair. 0 que chama atenção é a luta, o romance. Eu percebi agora isso... essa questão política (Estudante 4).

Os alunos que participaram do debate constroem, em diálogo, suas interpretações da obra. As questões da alienação, do controle da mídia e da política do país aparecem como reflexo de uma sociedade parecida com a Panem da ficção. No entanto, essas reflexões só acontecem quando, por intermédio do grupo de pesquisa, os espectadores são questionados e provocados para que saiam do nível da primeira leitura. Uma interpretação mais superficial abordaria a questão das lutas entre os distritos e a vitória do amor. Porém, no decorrer das discussões, os alunos analisam estruturas mais profundas da narrativa, buscando sentidos além do que está aparente, tanto no filme, quanto no livro.

A maioria dos alunos que assistiu ao filme já havia lido a obra impressa. Alguns dizem, até mesmo, que para que se compreenda a história melhor, é preciso ler e ver Jogos Vorazes. Mesmo sendo as linguagens tão peculiares, a experiência que se tem diante do texto escrito é bastante diferente da que se tem diante da imagem. Embora alguns questionassem a fidelidade da tradução, foi preciso pontuar que ambos os textos têm suas especificidades e, portanto, são obras distintas.

Sobre a literatura de massa e o cânone, foi possível observar algumas concepções trazidas pelos alunos:

Autores como Machado de Assis são mais eruditos, as palavras são mais complicadas (Estudante 1). 
Jogos Vorazes é mais próximo da realidade dos jovens (Estudante 2).

Não que essa obra seja inferior aos clássicos. É que eles são mais selecionados (Estudante 3).

Há preconceito com quem lê os clássicos. Com esses livros, tipo os do John Green, não precisamos pensar muito. É fácil de ler. Clássicos... você já demora mais. Mas os dois são legais (Estudante 4).

No discurso dos estudantes, pode-se identificar o valor atribuído à literatura erudita, visto que as obras parecem ser mais 'selecionadas'. A distância entre o vocabulário do cânone e as palavras utilizadas na literatura de 'massa' parece colaborar para que esses livros permaneçam, de certa forma, inalcançáveis para alguns. A ideia da supremacia delas, no entanto, fica evidente quando o aluno diz que é fácil ler a literatura produzida para a massa e que, ao fazê-lo, não é necessário pensar muito.

É possível enxergar, consequentemente, que os alunos reconhecem a diferença entre as obras valorizadas pela instituição escolar e aquelas pelas quais se interessam mais. Haveria, então, uma forma de levar esses alunos a buscarem no cânone leituras tão significativas quanto aquelas que eles fazem dos bestsellers?

\section{Em busca de uma conclusão}

A hierarquização das obras literárias e a áurea sagrada do impresso parecem impedir que as práticas de ensino de literatura na escola sejam atualizadas. Isso não quer dizer que o livro deixará de existir ou de ocupar papel importante na formação de leitores, mas que outros meios de produção e representação literária fazem parte da vida dos alunos e isso não pode passar despercebido pela instituição escolar.

Pela análise dos discursos dos alunos participantes da mostra de Jogos Vorazes, é possível perceber que eles têm conhecimento de que há uma diferença entre as literaturas de 'massa' e canônica, parecendo, inclusive, atribuir maior valor a essa última, o que não faz com que a distância que existe entre as obras 'sagradas' e o grande público diminua. Sabe-se que o número de leitores de obras clássicas é muito menor se comparado ao número de leitores de obras como Jogos Vorazes. Seria possível, no entanto, partir dessas obras e do diálogo 
que elas podem fazer com outras, a fim de oferecer mais opções ao leitor, sem desmerecer sua bagagem de leitura? Em um primeiro momento, pode-se observar que a discussão sobre a recepção da literatura popular pelos alunos traz boas reflexões para que seja possível repensar as estratégias de ensino nas aulas de literatura.

Certamente, muitas pesquisas ainda são necessárias para que as práticas de letramento literário sejam redimensionadas nas escolas. Para que isso ocorra, é preciso que o professor, enquanto mediador de descobertas, esteja disposto a reconhecer o universo dos seus alunos para, a partir daí, convidá-los a desbravar outros espaços. 


\section{Referências}

AZEVEDO, Ricardo. Formação de leitores e razões para a literatura. In: SOUZA, Renata Junqueira de (org.). Caminhos para a formação do leitor. São Paulo: DCL, 2004.

CANDIDO, Antonio. O direito à literatura. Vários escritos. 4a ed. São Paulo/Rio de Janeiro: Duas Cidades/Ouro sobre Azul, 2004, p. 169-191.

CEREJA, William Roberto. Uma proposta dialógica de ensino de literatura no ensino médio. 2004. 330 p. Tese de Doutorado. PUC São Paulo. Disponível em: http://www. virtual.ufc.br/solar/aula_link/Ilpt/Q_a_Z/semi_pesq_aplicada_ens_literat/aula_021485/imagens/01/cereja.2004.pdf. Último acesso em 24/08/2015.

COLLINS, Suzanne. Jogos Vorazes. Tradução de Alexandre D’Elia. Rio de Janeiro: Rocco Novos Leitores, 2010.

COSSON, Rildo. Letramento literário: teoria e prática. São Paulo: Editora Contexto, 2012. KRESS, Gunther. Multimodality. In: COPE, Bill; KALANTZIS, Mary. (org.) Multiliteracies. Literary learning and the design of social futures. London/ New York: Routledge, 2000. Pp. 182-202.

OLIVEIRA, Gabriela Rodella de. O professor de português e a literatura: relações entre formação, hábitos de leitura e prática de ensino. 2008. 317 p. Dissertação de Mestrado. USP. Disponível em: http://www.teses.usp.br/teses/disponiveis/48/48134/tde07102008-101148/pt-br.php. Último acesso em 24/08/2015.

PAULINO, Graça. Letramento literário: por vielas e alamedas. Revista da FACED, n. 5, Salvador: FACED, 2001.

SOARES, Magda. "Ler, verbo transitivo". In: PAIVA, Aparecida; MARTINS, Aracy; PAULINO, Graça; VERSIANI, Zélia. (Orgs.). Leituras literárias: discursos transitivos. Belo Horizonte: Autêntica, 2005. p.127-144. 